\title{
Ex-vivo evaluation of the three-column concept in canine thoracolumbar fractures
}

[Avaliação em ex-vivo do conceito dos três compartimentos em fraturas toracolombares da coluna]

G.A.C. Diamante ${ }^{1}$, P.V.T. Marinho ${ }^{2}$, C.C. Zani ${ }^{3}$, M.V. Bahr Arias ${ }^{4}$

\author{
${ }^{1}$ Faculdade de Medicina Veterinária e Zootecnia - Universidade de São Paulo - São Paulo, SP \\ ${ }^{2}$ Instituto Federal de Educação, Ciência e Tecnologia do Sul de Minas Gerais - Muzambinho, MG \\ ${ }^{3}$ Cirurgiã veterinária autônoma - Muzambinho, MG \\ ${ }^{4}$ Universidade Estadual de Londrina - Londrina, PR
}

\begin{abstract}
Traumatic events such as a motor vehicle accident or falling from heights are very common in veterinary medicine and often lead to vertebral fracture-luxation with concomitant spinal cord injuries, mostly in the thoracolumbar spine. The purpose of this cadaveric biomechanical study was to determine the feasibility of the three-column concept in canine thoracolumbar segments with induced fractures. Eighteen Functional Spinal Units (FSU) of the thoracolumbar segments (T12-L2) were collected from 18 medium-sized adult dog cadavers and were subjected to flexion-extension and lateral bending tests so that range of motion (ROM) was recorded with a goniometer. Fractures were induced by compressive loads applied by a universal testing machine (EMIC®). After this, specimens were screened using computed tomography (CT) and the fractures were graded as affecting one, two or three columns, and divided into groups A, B, and C, respectively. Post-fracture range of motion (ROM) was compared with the previous results. Groups B and $\mathrm{C}$ (with fractures in two or three columns) had instability in the two axes evaluated $(\mathrm{P}<0.05)$. The outcomes of this study support the applicability of the three-column theory to thoracolumbar spines of dogs, as the FSUs that suffered fractures in two or more columns showed axial instability.
\end{abstract}

Keywords: dogs, neurology, spinal cord, luxation, spinal fracture

\section{RESUMO}

Eventos traumáticos, como acidentes automobilísticos ou quedas, são muito comuns na medicina veterinária e, frequentemente, levam a fraturas ou luxações vertebrais, associadas a lesões medulares concomitantes, mais frequentemente na coluna toracolombar. O propósito deste estudo biomecânico em cadáveres foi determinar a viabilidade da teoria dos três compartimentos em fraturas induzidas em segmentos toracolombares de cães. Dezoito unidades espinhais funcionais (UEF) de segmentos toracolombares (T12-L2) foram coletadas de 18 cadáveres de cães adultos de médio porte e submetidas a testes de flexão-extensão e curvamento lateral, de modo que a amplitude de movimento (ADM) foi registrada com um goniômetro. Fraturas foram induzidas por meio de cargas compressivas aplicadas por uma máquina universal de ensaios (EMIC ${ }^{\circledR}$ ). As amostras foram submetidas à tomografia computadorizada (TC), e as fraturas foram classificadas como afetando um, dois ou três compartimentos e divididas nos grupos A, B e C, respectivamente. A ADM pós-fratura foi comparada com os resultados prévios. Os grupos $B$ e C (com fraturas em dois ou três compartimentos) apresentaram instabilidade nos dois eixos avaliados $(P<0,05)$. Os resultados deste estudo corroboram a aplicabilidade da teoria dos três compartimentos para segmentos de coluna toracolombar em cães, uma vez que as UEF que sofreram as fraturas em dois ou mais compartimentos apresentaram instabilidade axial.

Palavras-chave: cães, neurologia, medula espinhal, luxação, fratura de coluna

Recebido em 25 de julho de 2019

Aceito em 10 de dezembro de 2019

E-mail: gdiamante@gmail.com 


\section{INTRODUCTION}

Vertebral fractures or luxation with concomitant spinal cord injuries are very common in veterinary medicine and due to anatomical and biomechanical features, 52 to $58 \%$ of these injuries affect the thoracolumbar spine. Related consequences may vary from pain to permanent paraplegia, according to the lesion's severity and location (Bali et al., 2009; Mendes and Arias, 2012).

Treatment decision for vertebral fractures and luxation (VFL) is based on the patient's neurological condition and the biomechanical conditions on the fracture site. Surgery is indicated when there are unstable fractures or spinal cord compression, but there is still much controversy concerning indication to treat some fractures operatively, especially in patients without neurological impairment. (Jeffery, 2010; Weh and Kraus, 2018).
The well-known three-column concept was first proposed in medicine by Denis, (1983), in a retrospective radiological documentation. This theory was adapted by Shores et al., (1990) to veterinary medicine almost three decades ago without proper biomechanical validation. Since then, it has been considered one of the main classification systems of spinal fractures in dogs and cats (Jeffery, 2010; Fletcher et al., 2016; Weh and Kraus, 2018).

Due to scarce of biomechanical studies of the thoracolumbar spine in veterinary medicine and because there are important anatomic differences between humans and dogs (Figure 1), the objective of this study was to assess the applicability of the three-column concept to thoracolumbar fractures in spinal units from dog cadavers. We hypothesized that despite anatomical differences, the three-column theory can be applied to thoracolumbar spinal fractures in dogs.

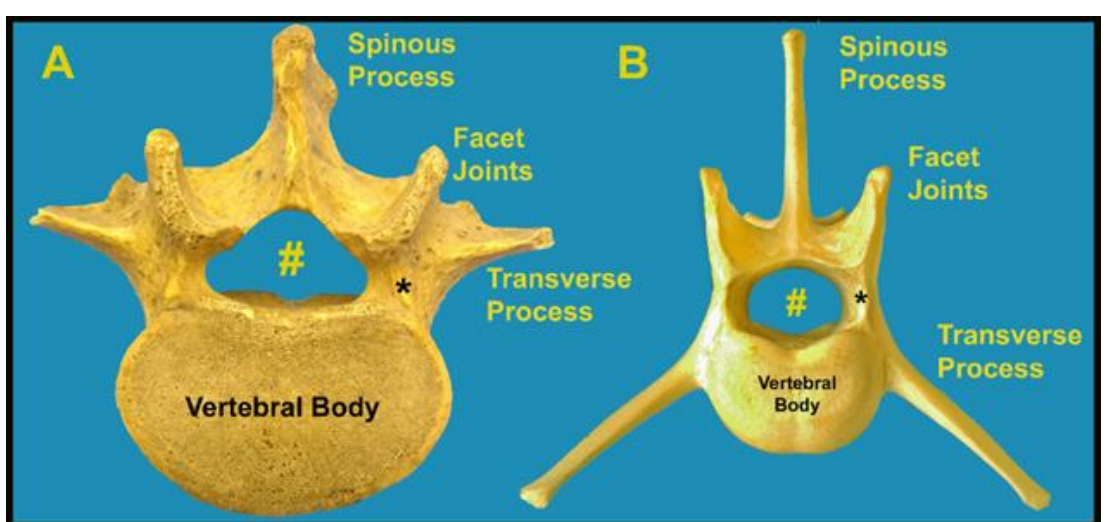

Figure 1. Comparative Image of human lumbar vertebrae (A) and canine lumbar vertebrae (B), showing anatomical differences between spines. Dogs have a smaller vertebral body and pedicles (*) size, as well as the lateral insertion of the transverse processes into the vertebral body instead of into the dorsal arch. The spinal canal (\#) in humans presents a triangular shape, unlike the dog which has an oval shape.

\section{MATERIAL AND METHODS}

This study was approved by the institutional animal care and use committee (IACUC), under protocol n-11067.2017.16. Eighteen middle-sized dogs that were euthanatized for reasons unrelated to this project were included in this study with owner's consent. Their body weight $(\mathrm{BW})$ ranged from nine to $15 \mathrm{~kg}$ (mean $\mathrm{BW}=11.82 \mathrm{~kg}$ ) and age ranged from 1.7 to nine years (mean age $=4.5$ years).
A functional spinal unit (FSU) is, according to the literature, the smaller portion of the spine for which biomechanical values can be extrapolated for the entire segment (White and Panjabi, 1990; Atlas et al., 2003; Grauer and Panjabi, 2003). The FSU chosen for this study consisted of the adjacent vertebrae T13-L1 and their intact interconnecting disc, facet joints, interconnecting ligaments and muscles. 
Specimens were harvested from the patients up to 48 hours after death. The cadavers were kept refrigerated until specimens were collected. Parallel skin incisions were performed with a scalpel blade adjacent to the thoracolumbar vertebrae. Muscle fascia and musculature were incised and dissected up to the limit of the transverse processes. Osteotomy of the ribs was performed and the whole T12-L2 segment was harvested in bloc. Disarticulation occurred at T11T12 and L2-L3 levels so the muscles around T12 and L2 were dissected. Nevertheless, the hypaxial and epaxial musculature at T13-L1 level (FSU) was preserved along with the corresponding vertebral ligaments (supra-spinous and interspinous ligaments, plus ligamentum flavum) and joint capsule.

All FSU collected were molded into selfpolymerizing poly (methyl methacrylate) (PMMA), in a 50mm-diameter PVC cast, to be later rigidly fixed to the test table. The cranial part of T12 and the caudal aspect of L2 were molded into the polymer. Correct horizontal alignment of the disc space in the dorsal and sagittal planes was secured before the hardening reaction (Figure 2).
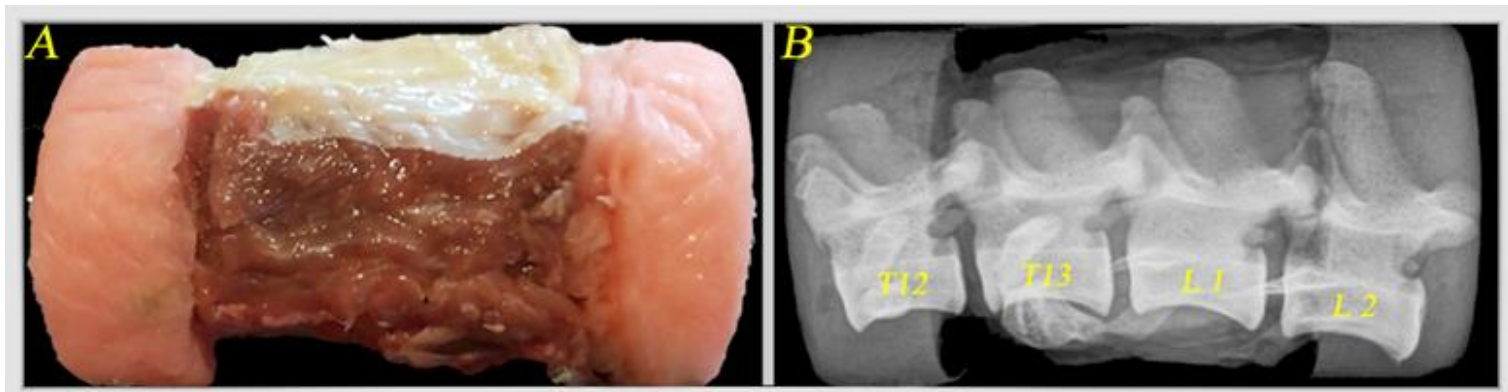

Figure 2. A. Photographic image of an FSU, consisting of two adjacent vertebrae (T13, L1), intervertebral disc, ligaments and joint capsule, and vertebrae T12 and L2 fixed to the polymer (Pink). B. Radiographic FSU image, showing the polymer covering only vertebrae T12 and L2.

After collection and preparation, FSUs were sealed in plastic bags, identified, and stored at $20^{\circ} \mathrm{C}$ until testing. Twenty-four hours prior to testing all samples underwent computed tomography (CT) scan to rule out any concomitant undiagnosed orthopedic lesion. The specimens were then stored in a Styrofoam box filled with ice, and after 12 hours, were thawed at room temperature.

Specimens were mounted over a custom apparatus attached to the testing machine by their cranial part (T12). Before fracture was created, multidirectional range of motion (ROM) was assessed by an observer (GACD) in all FSUs by aid of a goniometer. ROM was defined as the displacement exhibited by the FSU under the largest load manually applied by an examiner, measured in degrees. All FSUs were perpendicularly attached to the test fixture, with their dorsal aspect towards the examiner. A goniometer was then dorsally positioned in the FSU and right and left lateral bending ROM were recorded (Figure 3A). Next all FSUs were rotated $90^{\circ}$ counter clock and the goniometer was repositioned to measure the flexion-extension ROM.

Fractures were induced using the machine assisted compressing method, adapted from Shirado et al., (1992). Specimens, potted at the caudal aspect of L2, were fixed to the test table of a servohydraulic DL10.000 Universal Testing Machine (EMIC®). Axial compressive loads were applied to the unconstrained cranial portion (T12) of the specimens by the test apparatus' loading cell at a rate of $10 \mathrm{~mm} / \mathrm{min}$ until failure. Loads ranged from $802.59 \mathrm{~N}$ to $3634.87 \mathrm{~N}$ with mean load of 1787.35 $\mathrm{N}$. Tests were manually interrupted when failure occurred, defined either by a brittle change on the force deflection curve or by the cracking sound of bone fracture.

As there is no validated model for the induction of vertebral fractures in dogs, loads were applied in different angles, aiming to cause different fractures and in more than one vertebral compartment, according to the methodology used in a human (Panjabi et al, 1995). Thus, the units were randomly divided into four groups, and each group received one of the following loads: alpha 
$(\alpha)$ - six FSUs were loaded under axial compression force; Beta $(\beta)$ - four FSUs were compressed in a $15^{\circ}$ flexion angle directed from the axial plane towards the dorsal compartment (Figure 3B); Gamma $(\gamma)$ - four FSUs were compressed in a $15^{\circ}$ flexion angle directed from the axial plane towards the ventral compartment; and Delta $(\delta)$ - four FSUs were compressed in a $15^{\circ}$ flexion angle (from the axial plane towards the left lateral aspect of the vertebrae).

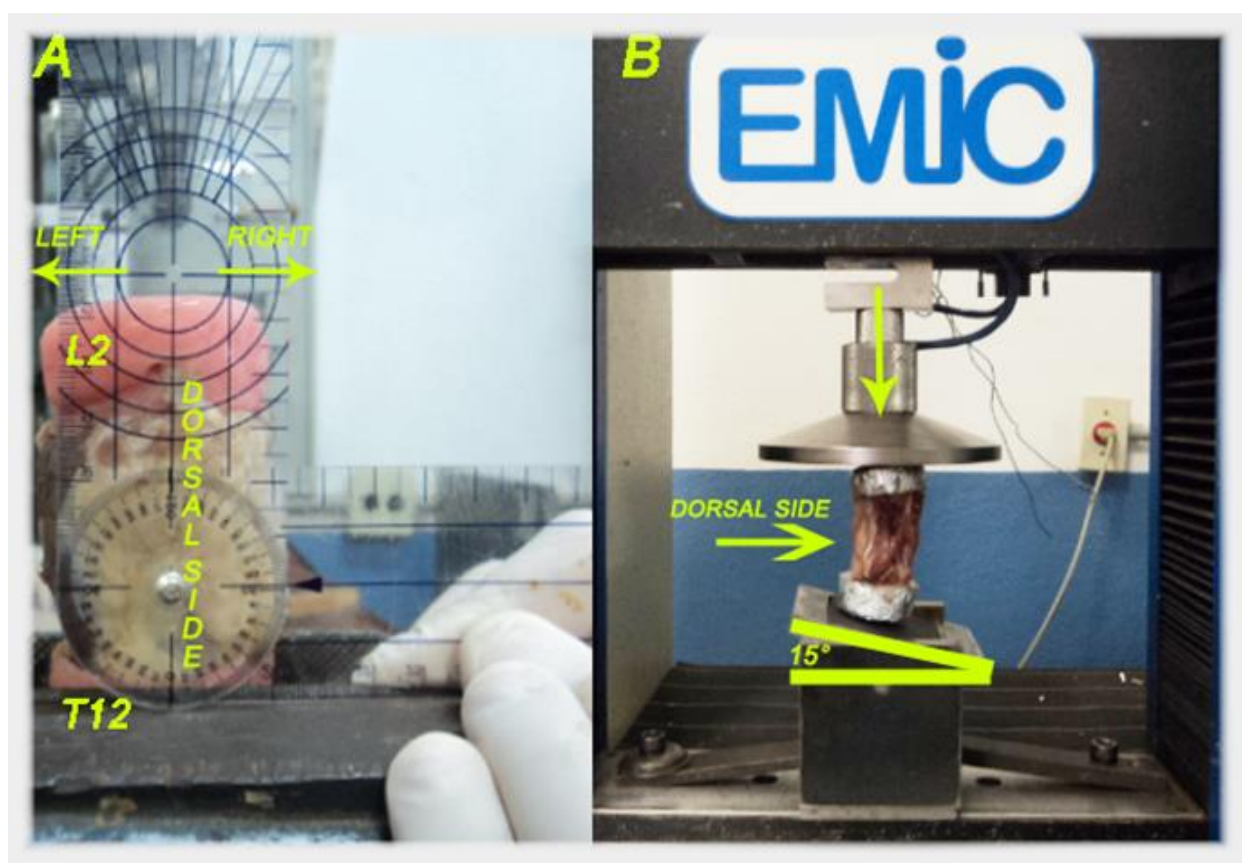

Figure 3. A. FSU fixation around the table, for vertebrae T12, with the goniometer placed in front of the dorsal region to measure the range of motion in the right and left lateral bending axis. B. An FSU placed on the universal testing machine EMIC, positioning the base at an angle of $15^{\circ}$ in the direction of the dorsal compartment (horizontal arrow), while applying a compression/flexion load.

After fracture occurred, ROM was reassessed in all the FSUs in the same manner as before the tests by the same observer (GACD). The observer was blinded to the number of compartments affected and type of fracture that resulted from the load applied.

Specimens underwent examination in a computed tomography (CT) scan (GE, Fxi Hispeed, one channel). Each $2 \mathrm{~mm}$ cross-section was evaluated using a standardized template adapted from Panjabi et al., (1995), to delimit the dorsal, middle and ventral columns, according to Shores et al., (1990). These columns were divided into 20 segments, 1-7 dorsal column, 8-11 middle column and 12-20 ventral column (Figure 4). A score was assigned to each segment on a scale from 0 to 2 : where 0 indicates intact, 1 partially fractured and
2 totally fractured. The dorsal column score was calculated by adding the scores given to segments 1-7 and dividing by 7 ; the middle column score was calculated by adding the scores given to segments $8-11$ and dividing by 4 ; whereas the ventral column score was calculated adding the score given to segments 12-20, and dividing by 9 . The final score of each column was the sum of the scores of the sections that presented a fracture.

All CT results were assessed independently by three observers (MVBA, PVTM, GACD), using a commercially available viewer software (Weasis v2.0.3) and the final grade was the average of total score of the observers. Fractures were also graded as affecting one, two or three columns, as proposed by Shores et al., (1990), and divided into three distinct groups, from A to C, respectively. 


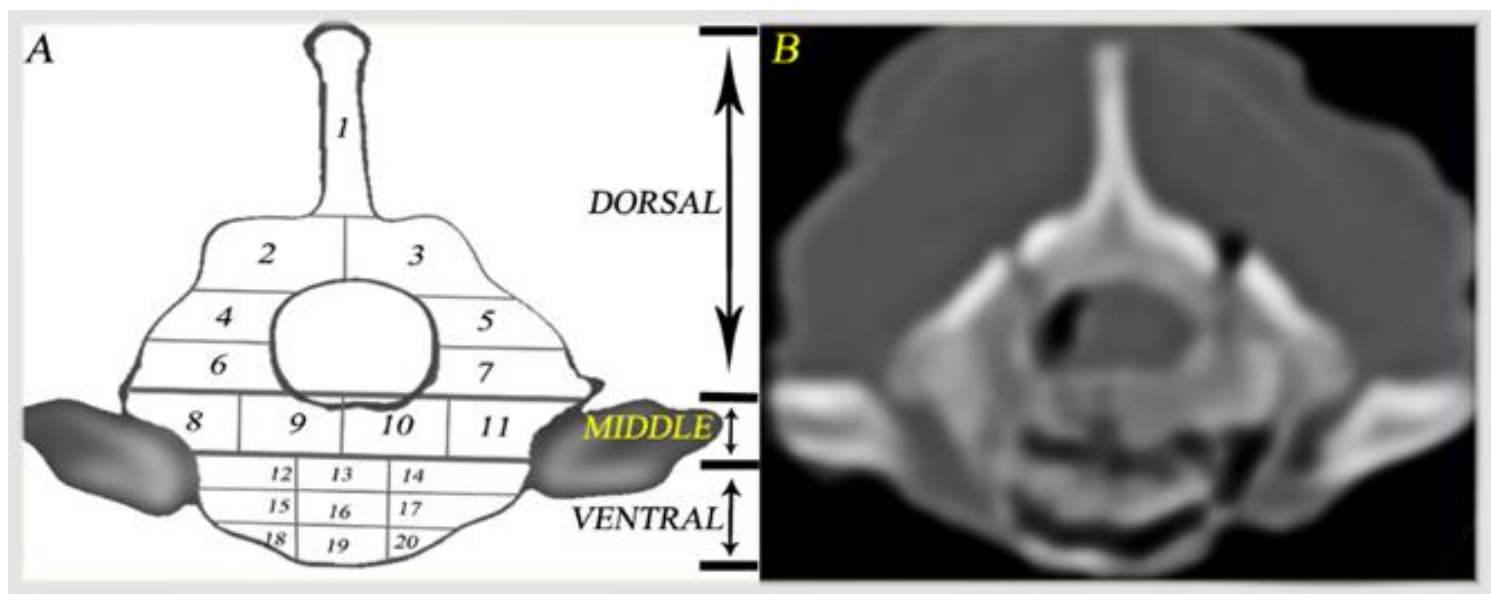

Figure 4. Fracture evaluation using computed tomography. A. "Template" used for thoracic vertebrae, divided into 20 segments: ventral column (12-20), middle column (8-11) and dorsal column (1-7). B. Example of an induced fracture involving the three columns of vertebra T13, cross-section view, showing a score of 0.7 in the dorsal column, of 1.5 in the middle column and of 1.22 in the ventral column.

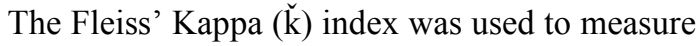
inter-examiner agreement as to the number of affected columns. Mean pre- and post-fracture ROMs (in flexion-extension and right and left lateral bending) were compared among groups using the paired $t$ test. Significance level was set at $\mathrm{P}<0.05$. Linear correlation test $(r)$ was used to assess the correlation between the obtained score in each column and the increased range of motion in the two tested axes. All statistical analyses were performed using $\mathrm{R}$ software, version x64 3.2.3, and Excel 2013.

\section{RESULTS}

Flexion-extension ROM of the fifteen intact specimens ranged from $14^{\circ}$ to $30^{\circ}$ (mean $22^{\circ}+/-$ SD $5.09^{\circ}$ ) with $23 \%$ of variation. Lateral bending ROM ranged from $18^{\circ}$ to $40^{\circ}$ (mean $27.6^{\circ}+/-$ $7.17^{\circ}$ ) with $26 \%$ of variation. Fractures were successfully produced in three spinal units in the first load protocol. Fifteen FSUs that had already undergone loading but remained intact were submitted to a second load protocol of increased speed. Twelve FSUs were fractured in this second test, the three remaining intact FSUs were excluded from further analysis. So, by the end, five FSUs were categorized as $\alpha$, three as $\beta$, four as $\gamma$ and three as category $\delta$.

Two FSUs displayed fractures in one column (group A), five FSUs in two columns (group B) and eight FSUs in three columns (group C). Fracture morphology significantly varied among the tested specimens and no specific fracture pattern could be attributed to the compared groups. Specimens categorized as $\alpha$, (tested under axial compressive load) had the highest injury score affecting all three columns, followed by categories $\gamma, \beta$ and $\delta$, respectively. Category $\beta$ displayed the second highest dorsal injury score and category $\gamma$ the second highest ventral injury score (Table 1).

Table 1. Categories based on the type of compressive load applied and the respective fracture scores. $\alpha$ : Right compression; $\beta$ : Base angled $15^{\circ}$ in dorsal direction; $\gamma$ : Base angled $15^{\circ}$ in ventral direction and $\delta$ : Base angled $15^{\circ}$ in left lateral direction

\begin{tabular}{|c|c|c|c|c|c|}
\hline \multicolumn{6}{|c|}{ Scores } \\
\hline Categories & Load & Dorsal & Middle & Ventral & Total \\
\hline A & Axial & 2.938 & 5.03 & 4.142 & 12.11 \\
\hline B & $15^{\circ} \mathrm{D}$ & 2.683 & 1.776 & 1.033 & 5.493 \\
\hline$\Gamma$ & $15^{\circ} \mathrm{V}$ & 0.972 & 2.997 & 2.797 & 6.767 \\
\hline$\Delta$ & $15^{\circ} \mathrm{LL}$ & 0.966 & 2.023 & 2.293 & 5.283 \\
\hline
\end{tabular}


Post-fracture ROM tests in flexion-extension ranged in group A from $32^{\circ}$ to $38^{\circ}$ (mean $35^{\circ}+/-$ $4.24^{\circ}$ with $12.1 \%$ of variation; in group B from $24^{\circ}$ to $50^{\circ}$ (mean $38^{\circ}+/-10.02^{\circ}$ with $26 \%$ of variation; and in group $\mathrm{C}$ from $38^{\circ}$ to $70^{\circ}$ (mean $47.12^{\circ}+/-$ $10.54^{\circ}$ with $22 \%$ of variation. Post-fracture ROM tests in lateral bending ranged in group A from $30^{\circ}$ to $36^{\circ}$ (mean $33^{\circ}+/-4.24^{\circ}$ and $12.85 \%$ of variation; in group B from $36^{\circ}$ to $64^{\circ}$ (mean $48.4^{\circ}$ $+/-11.17^{\circ}$ with $23 \%$ of variation; and in group C from $50^{\circ}$ to $80^{\circ}$ (mean $58.87^{\circ}+/-10.94^{\circ}$ with $18.59 \%$ of variation (Figure 5 ).

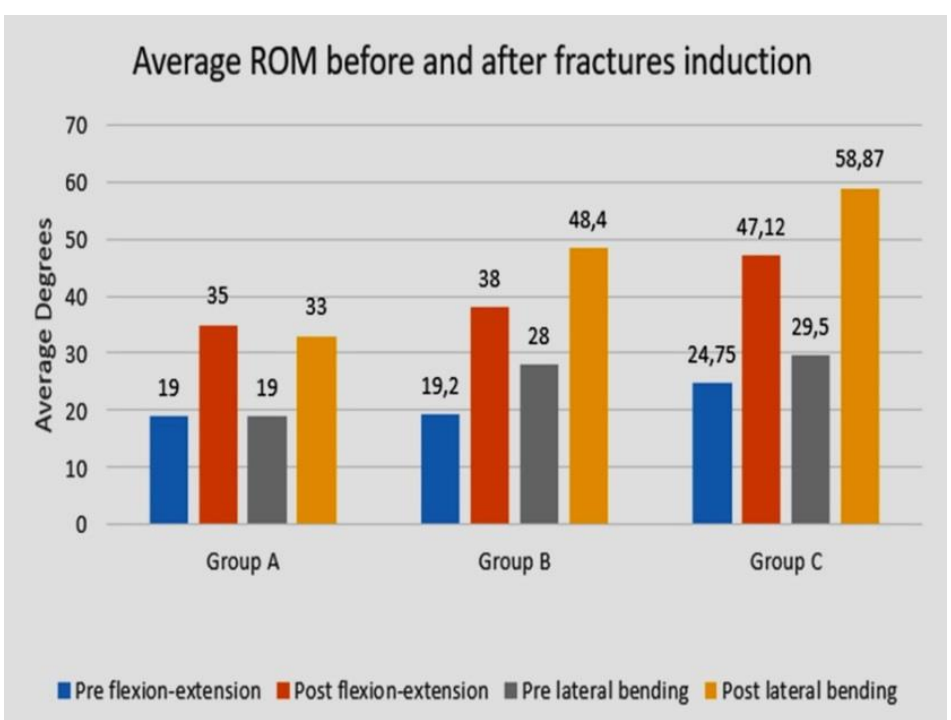

Figure 5. Graphic result of the average range of motion in groups A, B and C, before (blue) and after (orange) fracture induction in the flexion-extension axis, and before (grey) and after (yellow) fracture induction in the lateral bending axis.

There was a positive correlation, from moderate $(\mathrm{r}=0.5-0.7)$ to strong $(\mathrm{r}=0.7-0.9)$, among scores given by the evaluators when analyzing the columns involved. Kappa (k) index was used to assess evaluators' agreement on the number of affected columns and there was almost perfect agreement. Pre- and post-fracture ROM in flexion-extension and lateral bending were statistically different in groups B (two columns) and $\mathrm{C}$ (three columns), indicating vertebral instability. The same did not happen to group A (one-column fracture), which could indicate spinal stability. There was no correlation between the scores of each column and the increased ROM of each axis (Figure 6).

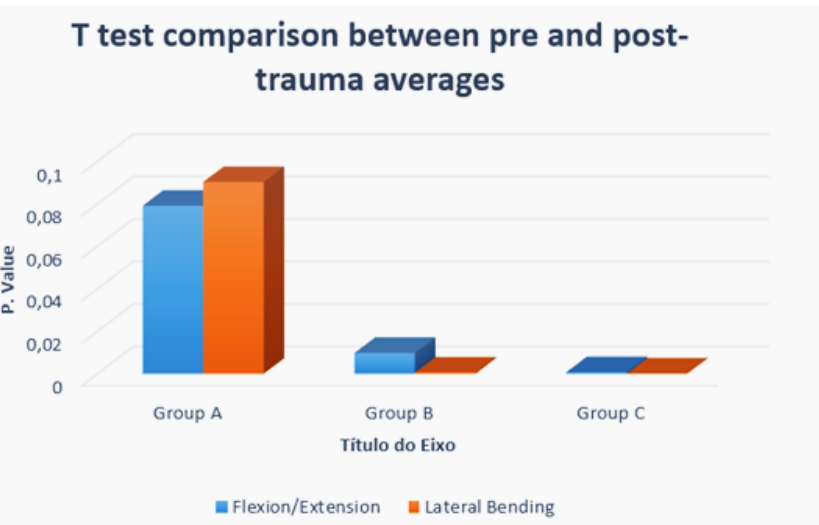

Figure 6. T test result comparing the average range of motion of groups $\mathrm{A}, \mathrm{B}$ and $\mathrm{C}$ before and after fracture induction, in flexion-extension (blue) and lateral bending (orange) axes, considering a level of significance of $5 \%$. 


\section{DISCUSSION}

The outcomes showed in this study support the applicability of the three-column theory for thoracolumbar spines of dogs, since the FSUs that suffered fractures in two or three columns demonstrated axial instability on flexionextension and lateral bending and the one-column fracture group remained stable in the same axis.

A challenge in vertebral biomechanical studies is to obtain standardized fractures that affect similar places in real patients with similar morphological characteristics, so that comparisons with intact vertebrae can be performed. To address such problem, testing models are necessary and in vitro fractures must be produced to mimic real-life situations. There are several trauma induction methods described in literature for the thoracolumbar region, inducing only one trauma or several traumas: machine-assisted compression of specimens, as used in this study, dropping weights of variable heights and manual osteotomy, although the clinical relevance of the last one is questioned (Fakurnejad et al., 2015). (Panjabi et al., 2000; Atlas et al., 2003).

A functional spinal unit (FSU) is the smaller portion of the spine that represents the entire segment and for which values can be extrapolated. It is formed by two adjacent vertebrae, their ligaments, articular capsule, and intervertebral disc (Schulz et al., 1996; Grauer and Panjabi, 2003; Busscher et al., 2010). Nevertheless, the number of vertebrae used in FSUs varied across studies and some authors used two, three or even four vertebrae in their research models.(Panjabi et al., 1995; Schulz et al., 1996; Atlas et al., 2003; Sturges et al., 2016). In this study, four vertebrae (T12-L2) were used as the testing unit, and vertebral ends were potted to acrylic and the two central vertebrae were left unconstrained.

In our research, two traumatic events were induced and the specimens that fractured in the first event were not loaded a second time. The test table was angled in $15^{\circ}$ to produce different types of fractures and overload different columns. However, the highest score produced in the three columns was obtained with perpendicular axial compression, a result that differed from that obtained by Panjabi et al. (1995) in human spines, who observed higher scores in all columns when the table was angled at $15^{\circ}$ towards the direction of the anterior column. Nevertheless, the authors used the "drop tower" method to induce fractures, which is different from that used in this study.

One of the main limitations of an in vitro spinal study is to define "instability". The term is defined in vivo as the inability to maintain spinal integrity under physiological loads, without vertebral displacement or worsening of neurological symptoms (White and Panjabi, 1990; Panjabi, 1992). The use of biomechanical methods to define a specific instability feature is challenging. Vertebral instability is defined in vitro as supraphysiologic motion of the specimens (White and Panjabi, 1990). Based on such assumption, we defined instability as the occurrence of a significant difference between pre- and postfracture ROM of the FSUs as in a similar study done by Kifune et al. (1995).

In this study the ROM was used to characterize the loaded column performance in each axis. In several studies the ROM has been divided into the neutral zone (NZ) and elastic zone (EZ). The ROM or NZ can be used to evaluate the displacement of a loaded FSU in biomechanical tests (Panjabi, 1992; Panjabi et al., 1995; Meij et al., 2007).

Load application and motion assessment on the FSUs are achieved in some studies by different custom-made equipments, which included a hydraulic system with oscillating arms developed to produce lateral bending moments (Schulz et al., 1996), and testing apparatus that permit the precise application of pure moments to the vertebral column or flexion devices produced to mimic spinal motions on the three axis (Benninger et al., 2004; Meij et al., 2007; Busscher et al., 2010), among others. ROM's measurements were effectively performed in our study by a goniometer. The authors did not find any studies that compared the sensitivity or effectiveness of this method with that previously cited. The lack of a pre-defined magnitude to apply the loads is one of the limitations of this study.

The samples were frozen and thawed twice, because some of the FSUs were subjected to more than one load protocol. It has been proven that such freeze/thaw process does not affect the biomechanical properties, either in the short or the long-term (Hirsch and Galante, 1967; Panjabi et al., 1985), nevertheless, the freeze/thaw cycles 
were reduced to a minimum. The standardization of the samples is important, as degenerative processes may alter the spine's biomechanical properties. To avoid this undesired interference, dogs older than nine years of age were not included in our study, which could cause increased spinal stiffness inherent to aging (Gillett et al., 1988). Body weight was also standardized and ranged from nine to $15 \mathrm{~kg}$, as vertebral stiffness positively correlates with the patient's size.

Since breed and gender have uncertain effects (Schulz et al., 1996), in this study, they were not taken into account. Moreover, a tomographic examination was performed in all specimens before testing to rule out patients with anatomical abnormalities, due to pathological or traumatic processes not previously diagnosed.

Fractures were quantified in scores in each compartment, to assess if any of the three columns would have more influence on increasing postfracture ROM. However, no correlation was observed between the affected columns in relation to the increased ROM in both axes evaluated, a result different from Panjabi et al. (1995), who observed a strong correlation between a higher score of the middle column with an increase in most of the flexibility parameters. This allowed the authors to infer that the middle column is the most important component for spinal stability in humans. This observation was verified by comparing the scores with the ranges of motion, as well as with NZ and EZ, in the three-column movement axes. Such difference may be due to the evaluation's method, since in vitro, the neutral zone is considered more sensitive (Panjabi, 1992; Kifune et al., 1995), or may have been a consequence of the anatomical differences between humans and canines.

An additional factor that could lead to these different results is the presence of the epaxial muscles, which were preserved in our FSUs, as these muscles promote spinal stability (Panjabi, 2003). This factor differed from all studies conducted both in humans and dogs, where muscles were removed from the specimens (only the ligaments were maintained) (Kifune et al., 1995; Panjabi et al., 2000; Meij et al., 2007). It was not possible to assess muscle influence on segmental stability, although it is believed that this method relates more to in vivo situations. On the other hand, the presence of muscles may interfere with the identification of a lab-induced fracture.

The middle column was not a determining factor in spinal instability; nevertheless, it is recognized as a limitation of the method used to assess ROM and also of the lack of assessment of axial rotation. However, since this study focused only on translational axis in flexion-extension and lateral bending, and didn't have the purpose to assess axial rotation, the findings cannot be extrapolated to all axes. Added to this limitation, it is worth highlighting the small number of specimens in group $\mathrm{A}$, and that only the dorsal columns were assessed in this category. This emphasizes the need for studies with more specimens, to compare the different affected columns, both separately and in group.

Although the three-column theory is widely accepted in veterinary medicine, it was adapted from studies performed in people (Denis, 1983; Shores et al., 1990; Jeffery, 2010; Weh and Kraus, 2018), despite the many anatomical and postural differences between species, without proper scientific evidence. Biomechanical studies in canine spines generally assess post-surgical stability or implant effectiveness used to stabilize fractures (Meij et al., 2007; Sturges et al., 2016). The present study is, to the best of our knowledge, the first study to assess the theory's applicability on dogs.

The outcomes of this study support the applicability of the three-column theory in thoracolumbar spines of dogs, as the FSUs that suffered fractures in two or more columns showed axial instability. The one-column fracture group remained stable. Further studies with a greater number of specimens and additional types of fractures are recommended to determine whether the instability, as defined in laboratory, could cause worsening of spinal cord injuries.

\section{ACKNOWLEDGEMENTS}

Special thanks to ND veterinary diagnostic center of Maringa, PR, Brazil, in particular to Glauber Camilo André, Solange A. Ascêncio Dalla Vecchia, Carmem L. Ascêncio, Doctor Denise Gomes de Melo, Jeferson Alessandro Godoy and Doctor Cláudio Cordeiro Albino for having kindly provided the equipment to carry out the 
tomographic examination in this study. We also thank Prof. PhD. Antônio Carlos Shimano for all the cooperation and for allowing the bioengineering laboratory of the Faculty of Medicine of USP in Ribeirão Preto, SP, Brazil to conduct this study. We thank to Prof. PhD. Alfredo L. Jacomo from Discipline of Human Structural Topography, department of Surgery, Faculty of Medicine of University of São Paulo in São Paulo, Brazil; for allowing us to photograph the human vertebrae to create de figure in this study.

\section{REFERENCES}

ATLAS, O.K.; DODDS, S.D.; PANJABI, M.M. Single and incremental trauma models: a biomechanical assessment of spinal instability. Eur. Spine J., v.12, p.205-210, 2003.

BALI, M.S.; LANG, J.; JAGGY, A.; SPRENG, D. et al. Comparative study of vertebral fractures and luxations in dogs and cats. Vet. Comp. Orthop. Traumatol., v.22, p.47-53, 2009.

BENNINGER, M.I.; SEILER, G.S.; ROBINSON, L.E. et al. Three-dimensional motion pattern of the caudal lumbar and lumbosacral portions of the vertebral column of dogs. Am. J. Vet. Res., v.65, p.544-551, 2004.

BUSSCHER, I.; VAN DER VEEN, A. J.; VAN DIEEN, J.H. et al. In Vitro biomechanical characteristics of the spine: a comparison between human and porcine spinal segments. Spine, v.35, p.35-42, 2010.

DENIS, F. The three column spine and its significance in classification of acute thoracolumbar spinal injuries. Spine, v.8, p.817$831,1983$.

FAKURNEJAD, S.; SCHEER, J.K.; PATWARDHAN, A.G. et al Biomechanics of thoracolumbar burst fractures: Methods of induction and treatments. J. Clin. Neurosci., v.21, p.2059-2064, 2015.

FLETCHER, D.J.; DEWEY, C.W.; COSTA, R.C. Spinal trauma management. In: DEWEY, C.W.; COSTA, R.C. (Eds.). Pratical guide to canine and feline neurology. Hoboken: Wiley Blackwell, 2016. p.688.

GILLETT, N.A.; GERLACH, R.; CASSIDY, J.J.; BROWN, S.A. Age-related changes in the beagle spine. Acta Orthop., v.59, p.503-507, 1988.
GRAUER, J.N.; PANJABI, M.M. Relevant clinical biomechanics of the spine. In: VACCARO, A.R.; BETZ, R.R.; ZEIDMAN, S.M. (Eds.). Principles and practice of spinal surgery. St. Louis: Mosby, 2003. p.896.

HIRSCH, C.; GALANTE, J. Laboratory conditions for tensile tests in annulus fibrosus from human intervertebral discs. Acta Orthop., v.38, p.148-162, 1967.

JEFFERY, N.D. Vertebral fracture and luxation in small animals. Vet. Clin. N. Am. Small Anim. Pract., v.40, p.809-828, 2010.

KIFUNE, M.; PANJABI, M.M.; ARAND, M.; LIU, W. Fracture pattern and instability of thoracolumbar injuries. Eur. Spine J., v.4, p.98$103,1995$.

MEIJ, B.P.; SUWANKONG, N.; VAN DER VEEN, A.J.; HAZEWINKEL, H.A.W. Biomechanical flexion-extension forces in normal canine lumbosacral cadaver specimens before and after dorsal laminectomy-discectomy and pedicle screw-rod fixation. Vet. Surg., v.36, p.742-751, 2007.

MENDES, D.S.; ARIAS, M.V.B. Traumatismo da medula espinhal em cães e gatos: Estudo prospectivo de 57 casos. Pesqu. Vet. Bras., v.32, p.1304-1312, 2012.

PANJABI, M.M. Clinical spinal instability and low back pain. J. Electromyogr. Kinesiol., v.13, p.371-379, 2003.

PANJABI, M.M. The stabilizing system of the spine. Part II. Neutral zone and instability hypothesis. J. Spinal Disord., v.5, p.390-397, 1992.

PANJABI, M.M.; HOFFMAN, H.; KATO, Y.; CHOLEWICKI, J. Superiority of incremental trauma approach in experimental burst fracture studies. Clin. Biomech., v.15, p.73-78, 2000.

PANJABI, M.M.; KRAG, M.; SUMMERS, D.; VIDEMAN, T. Biomechanical time-tolerance of fresh cadaveric human spine specimens. $J$. Orthop. Res., v.3, p.292-300, 1985.

PANJABI, M.M.; OXLAND, T.R.; KIFUNE, M.; ARAND, M.; et al. Validity of the three-column theory of thoracolumbar fractures. A biomechanic investigation. Spine, v.20, p.1122-1117, 1995. 
SCHULZ, K.S.; WALDRON, D.R.; GRANT, J.W.; SHELL, L. et al. Biomechanics of the thoracolumbar vertebral column of dogs during lateral bending. Am. J. Vet. Res., v.57, p.12281232, 1996.

SHIRADO, O.; KANEDA, K.; TADANO, S. et al. Influence of disc degeneration on mechanism of thoracolumbar burst fractures. Spine, v.17, p.286-292, 1992.

SHORES, A.; BRAUND, K.G.; BRAWNER JR, W.R. Management of acute spinal cord trauma. Vet. Med., v.85, p.724-739, 1990.
STURGES, B.K.; KAPATKIN, A.S.; GARCIA, T.C. et al. Biomechanical comparison of locking compression plate versus positive profile pins and polymethylmethacrylate for stabilization of the canine lumbar vertebrae. Vet. Surg., v.45, p.309318, 2016.

WEH, J.M.; KRAUS, K.H. Spinal fractures and luxations. In: JOHNSTON, S.A.; TOBIAS, K.M. (Eds.). Veterinary surgery small animal. [St. Louis]: Elsevier, 2018, p.2332.

WHITE, A.A.; PANJABI, M.M. Clinical biomechanics of the spine. Philadelphia: Lippincott, 1990. 